\title{
Resilience of Poultry Agribusiness to Climate Stress in the Nigeria
}

\author{
Achoja Felix Odemero ${ }^{1}$, Okpara Oghenesuvwe ${ }^{2}$
}

\author{
${ }^{1}$ Department of Agricultultural Economics and Extension, Delta state University, Asaba Campus, Nigeria. \\ ${ }^{2}$ Department of Animal Science, Delta state University, Asaba Campus, Nigeria.
}

\begin{abstract}
Today's poultry business is susceptible to heat and cold stress. Current production system often involves large numbers of birds being housed together making them susceptible to heat stress. Climate change stress causes death of the birds and reduced production. The paper clearly shows that increasing proportion of poultry farmers in the tropical and sub-tropical region adopt various adaptation measures on short term and long-term scales to enhance resilience of today's poultry agribusiness. The paper accentuates the potential use of naked neck and frizzle genes. Nutritional approaches to resilience such as feed intake, electrolytes and water balance or supplementing micronutrients such as vitamins and minerals to satisfy the special needs during climate change have been proven advantageous in this paper. Birds' thermo-tolerance to cycles of heat and cold conditioning or even feed restriction seems to be the most promising management methods in enhancing climate change resistance of poultry in the short run. It is recommended that there should be sensitization programs through workshops on resilience strategies of poultry agribusiness to clmate stress in the tropics.
\end{abstract}

Keywords - Resilience, Poultry, Agribusiness, Climate, Stress.

\section{INTRODUCTION}

The term resilience as used in the topic above means the ability to cope or manage stress (problems and challenges) due to climate change.

Dealing with changes or losses is an inevitable part of life. At some point, every poultry farm experiences vary degrees of setback due to one factor or the other. Some of the challenges may be relatively minor (not too severe) while others are disastrous on a more larger scale (diseases).How we deal with these problems or challenges can play a major role in not only the outcome of the poultry production but also in helping other small scale poultry production farmers. Farmers who lack this resilience may instead become overwhelmed by such experiences. They may dwell on problem and use unhealthy coping mechanism to deal with such challenges (World Poultry, 2010).

Resilience does not eliminate stress due to climatic change instead gives farmers the strength to tackle problems and overcome adversity and move on with their poultry production.

Current production methods often involves large numbers of birds being housed together making them susceptible to heat stress .Heat stress not only causes suffering and death of the birds but also results in reduced or lost production and hence adversely affects the profit from the enterprise. This write up discusses some of the key principles involved in reducing heat and cold stress. It embodies much of the latest advice and the best current husbandry practices. Stress comes in forms of severe cold or heat or a dramatic change form one factor to the other. Stress causes changes to occur in gut that lowers the PH. When PH is low, 'Gram negative' bacteria becomes more comfortable (WVA, 2005).

Poultry are more susceptible to stress than people realize. It infers with the birds comfort and suppresses production efficiency.

Birds kept in intensive conditions are constantly subjected to stress which is why farmers see such high mortality rates and have to pay out to keep birds health and make them productive.

Tolerance to heat stress is greatly influenced by high temperature and relative humidity in the air (Lavergn, 2014).

Also in this paper, specify body temperature regulatory mechanisms are discussed, as well as management considerations regarding facilities, fasting, management of water, and consumption, acid base balance, acclimation and diet composition. Poultry in hot climatic are exposed to high temperature, which may lead to a loss of productivity. Proper measures can be taken to manage conditions, but this demands an understanding of the bird physiology. 


\section{CAUSES OF HEAT STRESS}

High temperature and humidity combine to pose severe problems for all poultry type but older birds face a bigger risk. As the birds get older, they increase in size as well as insulation (feathering) which makes it harder for them to dissipate heat. The most obvious sign of heat stress in poultry is panting. Poultry do not have sweat gland that can cool their skin, so instead they must use evaporation from their throat and respiratory system as a means of cooling themselves (Lavergn, 2014).

Heat stress is one of the greatest environmental factors affecting the poultry production industry because it reduces egg production, egg quality, and safety. Birds under heat stress exhibit reduced feed intake. It results from an interaction among air, temperature, humidity, radiant heat and speed (Lin et al, 2006).

As the birds temperature rises feed intake decreased, reduced growth rate, poor feed conversion, reduced egg production, egg shell quality and size decreased, reduced hatchability rate and survivability declined. Many solutions have been sure proposed, but no sure cure exists for this dilemma. However, a variety of therapeutic approaches based upon sound physical and biological principles do indeed have the ability reduce the consequences of heat distress. Panting takes a lot of energy which in turn generate an appreciable amount of body heat for poultry. Ultimately, if poultry are not relieved of heat stress, their body temperature can continue to rise and increase the possibility of mortality (Czarick et al, 2000) .

\section{HEAT STRESS METHOD}

Radiation: This is the flow of thermal energy without the aid of a material between two surfaces. Losses are proportional to the temperature difference between the body surface and the surrounding surfaces. Thus, poorly insulated roofs increase house temperature and make heat stress worse in hot weather as does direct sun on free range birds.

Conduction: This is when thermal energy flow through a medium or between objects in physical contact. If the birds are seated on litter which is cooler than their bodies, heat will flow by direct surface to surface. However, the litter immediately under the birds soon assumes a temperature close to that of the body.

Convention: This is when heat flow through a fluid medium such as air, thermal energy moves by between a solid surface and the layer of air next to the surface, and thermal energy is carried away by the flow of air over the surface. Heat loss will occur from the natural rise of warm air from around a hot body. It can be assisted by providing moving air but only if the air moves fast enough to break down the boundary layer of still air which surround the body (Charles, 2002).

\section{Latent Heat Loss Method.}

Evaporation: This is the transfer of heat when a liquid is converted to a gas. When water is converted from a liquid to a vapour, heat is utilized. Such losses are very important at high temperatures. Poultry do not sweat, but they depend on panting, and this is only effective if the humidity is not too high. Hot humid conditions are therefore much more stressful than hot dry conditions.

\section{PHYSIOLOGICAL EFFECTS OF HEAT STRESS}

Modern commercial poultry production entails raising birds' intensity. This system permits many birds to be kept and cared for using relatively little space. The system however has it peculiar problems which stress the birds due to climate change; a hot environment is one of these important stress factors. When the optimum temperature requirements of birds are not met the birds start panting, spread their wings and squat close to the ground (Lin et al, 2006).

Panting removes heat by the evaporation of water from moist lining of the respiratory tract. However, panting itself generates body heat, and it causes birds to eliminate water from the body (Kenneth et al, 2007). It can induce respiratory alkalosis which occur because birds 'blow off' excessive carbon dioxide $\left(\mathrm{Co}_{2}\right)$ when it pants. As a result, body fluid becomes more alkaline causing the kidneys to excrete excessive amount of several electrolytes. Increase panting, which usually occurs when environmental temperature are near or above $30^{\circ} \mathrm{c}$, increases muscles thereby increasing the energy requirement of affected poultry. Increased panting also decreases the level of blood carbon dioxide thereby elevating blood PH (respiratory alkalosis), and alter the electrolytes balance of the blood, suppresses growth in broiler and decreases blood calcium and bicarbonate which are necessary for strong egg production in layers (Lin et al., 2006). In view of these adverse effects of heat stress, feed intake decrease affecting growth, production and overall performance of the bird(s). During hot climate periods evaporative heat loss typically becomes primarily method by which bird regulates their body temperature unless proper ventilation is produced and other steps taken to reduce heat stress. Stress causes changes to occur in gut that lowers the $\mathrm{PH}$. When $\mathrm{PH}$ is 
low, 'Gram negative' bacteria becomes more comfortable (WVA, 2005).

Birds are comfortable when environmental temperature is within the range of $18^{\circ} \mathrm{c}-24^{\circ} \mathrm{c}$, but with environmental temperature rising higher than upper critical limits (ie $24^{\circ} \mathrm{C}$ ), birds responds in the opposite way.

(i) Peripheral blood circulation (to skin, upper respiratory tract, abdominal muscles, combs and wattles) increases 2-4 times. Consequently blood flow to liver, intestine, kidneys is reduced.

(ii) Birds start panting (increase in respiratory and heart rates)

(iii) Birds stretch the body and take lying position closer to litter material and nearer to drinkers.

(iv) Water consumption increases by 1.2 to 3.2 times as per outside temperature.

The first three responses help in sensible heat loss and the last helps in internal cooling of the body system. However, with prolonged exposure to hot weather, these responses will lead to the following.

1. Reduced blood supply to visceral organ leads to;

(a) Poor weight gain, higher feed conversion rate due impaired digestion, and assimilation.

(b) Enteritis, reversal of blood weight due to SIBO (Small Intestinal Over Growth) (Lavergn,2012).

\section{Acid base imbalance in the body}

There is loss of $\mathrm{Co}_{2}$ because of continuous panting (alkaloidosis). Kidneys act to restore acid balance renal exchange of bicarbonate with $\mathrm{Cl}$ ion. This results in increased excretion of bicarbonates and retention of $\mathrm{Cl}$ in plasma and that lead to systemic acidosis. Thus heat stress initial alkaloidosis changes to systemic acidosis and birds die of acid shock.

In heat stress, supplementing diets with ammonium chloride (NH4Cl) $(0.3-1 \%+$ Sodium bicarbonate $(1-2 \%)$ is helpful since ammonium chloride reduce blood $\mathrm{PH}$ and sodium bicarbonate prevent excessive acidosis (Teeter et al,2000).

Along with bicarbonates, electrolytes are also excreted in urine because bicarbonates are negatively charged, and $\mathrm{Na}$ and $\mathrm{K}$ ions (important electrolytes) being positively charge go with it. Loss of electrolyte affects the water balance (Narsapur, 2012).

\section{Water imbalance in the body}

Normally water intake + water formed by oxidative metabolism in the body $=$ Water loss through urine, faeces, respiration and evaporation.

In heat stress water loss is more (60\% more) through urine and increased respiration. This results in dehydration (decrease in extra cellular fluid level), fall in blood volume, fall in blood pressure and increase in plasma osmolality. Body reacts to those changes by releasing rennin from the kidney cells and that increases thirst. Anti diuretic hormone (vasopressin) is released from the pituitary which reduces urine output by increasing water resorption in renal tubules. Even though birds drink more water, its retention in the cell is less because of loss electrolytes and organic osmolytes (betain, sorbitol inositol) as stated above. Negative water balance, prevents internal cooling and hence there is further rise in body temperature.

Supplementation of betain (osmolytes) and electrolytes helps in maintaining water balance in the body cells against extra cellular osmotic gradients (Narsapur, 2012).

\section{Immune suppression.}

In hot climate there is released of corticosteroids from adrenals and also depletion of plasma vitamin $\mathrm{C}$; and reduction in lymphocyte count. The effect is immune suppression (Narsapur, 2012).

\section{RESILIENCEOF POULTRY TO HEAT STRESS}

Ensure good ventilation with cool air.

Provide a comfortable environment for your poultry farm always. Make sure your poultry house is in well ventilated area in which there is nothing to obstruct the air flow. Placing poultry in a well ventilated area help reduce the incidence of heat stress (Lesson, 2000).

Also keep the ventilation system well cleaned, poultry netting on side walls or air inlets often will pick up dust to restrict air movement and should be cleaned regularly.

A well located and well laid out poultry farms, with trees and lawns around and getting breeze will have lesser problem in hot climate season. In addition roof insulation plus increased ventilation by fan would help to withstand moderate hot weather. In extremely hot climate, however, the above measures are not sufficient and evaporative cooling systems such as sprinklers, foggers or pad cooling are necessary. These systems work very well especially if relative humidity is low and temperature inside house can be brought down by $10-15^{\circ} \mathrm{c}$ (Narsapur,2012).

2. Daily management to prevent heat stress; In hot climate, the following measures are advised;

(i) Carefully select a proper time of feeding and withdrawing feed. Withdrawing feed from $9 \mathrm{am}-4.30 \mathrm{pm}$ is very effective in reducing heat stress mortality because during the late afternoon there is a significant rise in body temperature of the birds. Feed intake and digestion produces nearly $7 \%$ additional heat in the body which is maximum 45 hours after feed intake. This should not coincide with 
hottest part of the day (2-3pm).Birds fasted in the day compensate intake in the night time and it should be seen that light do not go off in the night. If bio-security is poor, feed withdrawal may lead to coccidiosis, necrotic, enteritis. Necessary medicines may be kept at hand in case such eventuality arises (Elsevier, 1996).

(ii) Have readily available, cool clean, quality drinking water.

Cool water (at $10-12^{\circ} \mathrm{c}$ ) should be supplied continuously to birds and must be in a location that is easily accessible to the birds. Watering space should be double, over head tanks and pipes system should be properly covered to keep the water cool. Birds reject warm water and that accentuates heat stress. Adding nutritional water supplement that runs continuously in hot climate is also of great benefit (Lesson, 2002).

Providing fresh cool water $\left(5^{\circ} \mathrm{c}\right)$ in noon time is very effective for internal cooling of the body (heat sinks) and reducing symptoms of stress (Narsapur, 2012).

It may also be useful to provide sufficient cool water in larger containers such as

\section{Preventive treatment through drinking water.}

Add nutritional supplements such as electrolytes to drinking water. The electrolytes balance in birds is altered during heat stress due to panting. Panting increases carbon dioxide loss in the bird, which reduces the bird ideal water intake. By adding electrolytes to the feed or drinking water, birds increases their water intake, which aids in keeping a constant body temperature and maintains an effective system of evaporative cooling (Teeter et al, 2000) Electrolyte is added in to the drinking water to replace those that are loss and to stimulate water consumption.

(a) In moderate hot weather

Ascorbic acid...........62.5 mg/litre

+ Acetylsalicylic acid $62.5 \mathrm{mg} / \mathrm{litre}$

+ Sodium bicarbonate $75 \mathrm{mg} /$ litre

+ Potassium chloride $(\mathrm{KCl}) 125 \mathrm{mg} / \mathrm{litre}$

(b) In heat stress

Vitamin C $400 \mathrm{mg} / \mathrm{litre}$

+ Electrolytes

+ Acetylsalicylic acid (Disprin 1 tablet/5litre

+ Sodium bicarbonate $1 \mathrm{~g} /$ litre........ may be used (Narsapur, 2012).

4. Stocking Density: Avoiding overcrowding your birds, loss often depends on the difference between the body temperature of the birds and the ambient temperature. If the stocking density is high, the radiant heat between the birds accumulates and the temperature increases. Therefore, the birds cannot loss body heat temperature. This will encourage radiant heat transfer from bird to bird while stagnant or stale air gets trapped between the birds (Defra, 2003). Do not exceed the recommended stocking densities. Where possible, reduce stocking density during hot climate both in poultry house and during transportation. Birds produce body heat, thus by reducing the number of birds in the poultry house you will reduce the amount of body heat produced in the house. (World poultry, 2010).

5. Birds Handling: During the hottest period of the day any additional stress on the birds should be avoided. Vaccination, beak trimming, restocking or any other kind of handling should be done during the coolest period of the day, if necessary at night. In any case, handle birds as calmly and gentle as possible. (ie cold chain should be maintained during transport, storage and administration of vaccines; should be carried out during cool hours).

6. Use of summer feed formula: Metabolic energy requirement decreases as ambient temperature increases to above $21^{\circ} \mathrm{c}$, resulting from a reduction of energy requirement for maintenance. The energy requirement

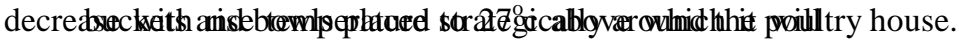
start to increase again since birds need additional energy for panting to reduce body heart.

In climate, feed should be made denser with nutrients, vitamins and minerals to compensate for reduced intake. Thus as the hot climate season progresses, it may be necessary fine tune feed formula again in moderate climate. Proteins generate greater metabolic heat when consumed than energy feeds do. Consequently, provision of feeds with lower protein: energy ratio during the hot periods of the day and high protein: energy diets during the cooler periods of the day will reduce heat stress (Basillo et al., 2001).

Feeding a wet diet has been found to increase dry matter intake of layers at temperatures (Tadtiyanant et al., 1991) and to improve egg production and egg weight. In broilers, a diet mixed water in a ratio of 1:5:1 (feed: water) significantly increased body weight gain, dry matter intake, carcass weight and carcass lipid content (Kutlu, 2001).

In addition the following features, which have bearing on heat stress control, should be included in summer feed formula.

\section{(a) Crude Protein.}

Crude protein level in feed should not be increased to minimize heat stress and maintain production; and protein from only vegetable source should be used. Protein in general and those from animal sources in particular have higher heat increment values (ie produce more internal heat in the body). 
Secondly vegetable proteins (soya, sesame, sunflower) are rich in arginine. Under heat stress arginine absorption is low and result in plasma amino acid adding to the body heat. Hence vegetable proteins are preferred in hot climate. While keeping protein level same, crucial amino acids may be increased to compensate for reduced feed intake (Narsapur, 2012).

(b) Fats and Oil.

Fat should be increased by $2-3 \%$ at the cost of carbohydrates without changing metabolic energy. Fats are good in hot climate because their heat increment value is lowest give better cooling effect in body because of higher water content and fat stimulates feed consumption. (Narsapur, 2012). Fat has also been shown to slow feed passage through the gastrointestinal tract and therefore increases nutrient utilization.

Including oil in the diet has long period to be beneficiary in hot climate and shows better effect than in moderate climates. For example, the inclusion of oil increase feed intake by $17.2 \%$ at $31^{\circ} \mathrm{C}$ compare to the $4-5 \%$ at temperature of $10-18^{\circ} \mathrm{C}$. Digestion of fat produces less heat than digestion of carbohydrates and protein (ie from animal sources). Oil binds the fine particles in the feed and stimulates feed intake. Additionally, it increases the energy intake due to less feed intake during the hotter periods; up to $5 \%$ oil can be used. An additional advantage of oil is the content of linoleic acid, which improves the production and weight of the eggs (Kenneth et al., 2007).

\section{(c) Vitamin $\mathrm{C}$ and Minerals.}

Vitamins are unarguably very important components of poultry's diet. It should also be noted that unless a formulated ration is used, it is likely that deficiencies will occur, negatively affecting the birds. Vitamin $\mathrm{C}$ is thought to support the birds in handling heat stress. Because of the release of corticosteroids in heat stress, there is increase demand for vitamin $\mathrm{C}$ by adrenal glands for controlled production of hormone needed for gloconeogenesis. Some birds may not be able to synthesize sufficient ascorbic acid to replace the severe loss of vitamins during heat stress. In heat stress there is also reduced synthesis and partial depletion of vitamin C. Inclusion of Vitamin C at 150-200$400 \mathrm{mg} / \mathrm{ton}$ of feed is recommended in hot climate months. If included in feed, there is no need to give; in water again (Narsapur, 2012).

Research in the nearly 1960's showed that an addition of vitamin $\mathrm{C}$ improved egg weight, shell thickness and egg production. Later experiments demonstrated that adding ascorbic acid in the feed formula improved feed intake and feed utilization. The optimal effect was shown by adding 250-400mg ascorbic acid/kg. Due to the lower feed intake at high temperature, a sufficient supple of vitamin has to be guaranteed. (Elsevier, 1996)

During the hot period, minerals excretion is usually increased. It is therefore advisable it increase the mineral level in the formula, since it is difficult to react fast enough through dietary changes, application via drinking water is recommended (World poultry, 2010).

\section{(d) Sodium bicarbonate}

It has a positive effect of increasing water intake, and also reducing systemic acidosis. It can also be given through feed instead of through drinking water. In vegetable feed, inclusion of sodabicarb at $0.4 \%$ (4 kg/ton) + Sodium chloride $0.25 \%(2.5 \mathrm{~kg} /$ ton $)$ would properly balance sodium and chloride level in feed (Narsapur, 2012).

\section{(e) Betain (Osmolyte) in feed}

Betain ( 0.5 to 1 gram/ton) help in maintaining water balance in the body cells against extra cellular osmotic gradient. Electrolytes also have similar action and better given through water (Narsapur, 2012).

\section{(f) Anti Oxidant}

In heat stress there is excessive oxidative metabolism and release of free radicals in the body. Free radicals damage all types of biological molecules, and cells of vital organs more so of immune system. Vitamin E captures and neutralizes free radicals and its inclusion at 50-100ppm in feed is advisable. Vitamin $\mathrm{C}$ also has antioxidant property. Similarly antioxidants namely BHA, BHT and EQ will protect fats and oils in feed from oxidative rancidity (Narsapur, 2012).

(g) Virginiamycin 15-20ppm in feed apart from being growth promoter, reduces metabolic heat production, alleviates heat stress and stimulates immune responses.

\section{(h) Anticoccidial}

Nicarbazine and Monesin are contraindicated in hot climate. The former decreases tolerance to heat and the latter depresses water intake.

(i) Biotin supplementation at $150 \mathrm{microgram} / \mathrm{kg}$ feed is recommended.

(j) Vitamin K supplementation is recommended particularly at time of debeaking or if there is threat of coccidiosis because of heat stress blood clotting time prolonged.

(k) Toxin binders: In wet climate, there is rapid growth and toxin formation in feed. Good quality toxin binders at higher dose should be used in feed (Narsapur, 2012).

Other associated problems in hot climate season

In hot climate season, apart from hot weather related ones, other associated problems could arise and the following precautions are necessary to address them. 
1. Regular sanitization of drinking water, periodic cleaning of water tanks and flushing pipe system. This is necessary since bacterial counts in water increases in hot climate due to water table going down.

2. Use of litter conditioner: In hot climate since there increase intake and excretion of water by birds. There is wet litter and ammonia problems in poultry house, hence it is important to maintain litter dry.

3. Decreased Litter Volume: Very thick litter in poultry kept on deep litter system tends to trap more heat at the floor level on hot days. By reducing the thickness of litter on the floor to just about 1 to $1 \frac{1}{2}$ inches, heat at the lower level of the poultry house can be reduced (Poultry one, 2008).

4. Immunostimulants should be given for three days following each vaccination.

5. Extreme measure: In extremely serious heat stress situations, birds may be sprinkled with water as a last resort. Any chicken which collapses as a result of heat stress should be dipped in a bucket of cold water (Poultryone, 2008).

6. Use of roof sprinklers: In places where water and electricity is constantly available, metal roofs can be sprayed mechanically with water on very hot days to reduce in-house heat in poultry houses by evaporative cooling (Poultryone, 2008).

Any management that increases nutrient intake during heat stress will minimize the drop in production efficiency. The three easy ways to increase consumption are;

(a) To increase the nutrient density of the ration.

(b) To take advantage of natural increases in feed consumption at certain time of the day and

(c) Adjust ventilation fans to provide more cooling during the evening.

\section{BUILDING CONSTRUCTION}

The building site, orientation, insulation, roof overhang, and equipment design all affect the temperature inside the poultry house. All poultry houses should be positioned so that the roof line runs from east to west. This orientation will help direct sunlight from coming through the sidewall and causing heat to build up within the house. Adequate insulation of the ceiling of the poultry house and sidewalls will pay dividends by reducing the amount of sun's radiant heat energy (solar heat) that reaches the interior (birds). Installing insulation to the end of a 24 inch roof overhang will prevent solar radiation from penetrating the sidewalls. Insulation also reduces heating cost during winter months
(McMullin, 2004). Vent must be provided to reduce heat and moisture build up above the insulation.

Another factor that affects heat gain of a poultry house is the condition of the roof. A shiny surface can reflect twice as much as a solar radiation as a rusty or dark metal roof. Roofs should be kept free of dust and rust, reflectivity of roof can be increased by cleaning and painting the surface with metallic zinc paint or by installing an aluminium roof. These practices are particularly effective for buildings that are under insulated. (Kenneth, 2007).

Equipment and Ventilation Techniques For Reducing Heat Stress.

During hot climate when the temperature and relative humidity are high, proper poultry house ventilation is vital to ensure the necessary removal of heat and the continued productivity of the flock. Poultry house ventilation system has a number of components. These include curtains (Tarpualine), fan, fogging nozzles, evaporating cooling pads, timers, static pressure controllers and thermostats.

Most ventilation system can provide an adequate indoor environment when properly managed. If the design and management of the ventilation system fails to satisfy the flock ventilation needs, stale, contaminated air can build up in the poultry house. Stale or contaminants include ammonia, moisture, carbon dioxide, carbon monoxide and dust; can cause stress and lead to depressed performance. Stress may impair the immune system and increase susceptibility to disease. To reduce problem with stale air and contaminants, air temperature, air speed and relative humidity must be controlled by careful management of the ventilation system (Kenneth, 2007).

\section{CAUSES OF COLD STRESS AND ITS EFFECTS}

As environment temperature dips below lower critical level (ie $18^{\circ} \mathrm{C}$ ) cold sensory receptors in the skin are stimulated, pass impulses to thermoregulatory centre in hypothalamus and that signals contraction of peripheral blood vessels. Thus blood supply to skin is diminished and sensible heat loss through skin is prevented. At further lower temperatures birds will not be able to conserve heat anymore and die due to chickens are at the risk for cold stress (Narsapur, 2012).

In extremely cold weather, birds under the extensive system of poultry are at the risk of frostbite, the possible consequences of frostbite are pain, disfigurement, loss of mobility, decreased fertility in the rosters and diminished egg production in layers. Mild cases are often unavoidable even with the best preventive efforts of diligent poultry 
farmer, but knowing the causes, how to optimize a flock's living condition and how to treat frostbite if it occurs will reduce the risks and limit any damage. In cold climate, bird are able to conserve body heat by restricting blood flow to their combs, wattles and feet, the very part of the body that give off excessive heat warm climate. The result is a decrease in warmth and oxygen to those extremities, which puts them at risk of frostbite. (Katty, 2013). Fortunately we do not experience extremely cold climate in the tropical region of Nigeria that could lead to frostbite.

\section{What is frostbite?}

Frostbite is the damage that occurs to bodily tissues from exposure to extremely cold when fluid cells freezes. As a result of freezing, blood clot from depriving the cell of oxygen, causing tissue damage to varying degrees. In extremely cold conditions exposed tissues can suffer frostbite in minutes (Katty, 2013).

Birds with large combs and wattle are especially vulnerable to frostbite, but any bird can be affected if the conditions are cold enough. Wattles are especially susceptible to frostbite since drinking water often drips from the beak, down the wattles.

\section{Contributing factors to frostbite.}

1. Freezing temperatures.

2. No access to shelter/ Wind chill factor.

3. A coop allows water, rain and snow to leak inside.

4. High humidity in coop from accumulation of droppings, not enough pine shavings.

5. Inadequate ventilation.

6. Large combs and wattles.

7. Inadequate roosting space.

8. Birds sleeping on the floor instead of the roosts.

9. Draft (current of cool air in a poultry house or other confined space (Tiily, 2013).

Signs and symptoms of frostbite.

1. Color change to tissues: Whitening/lightening, pale, grayish-yellowish or grayish-blue color.

2. Swelling.

3. Tissue may feel cold and / or hard to the touch.

4. Blisters filled with clear or milky fluid, which may not appear until 24-36 hours after exposure.

5. Blackened tissues.

6. Limping.

7. Loss of appetite.

8. Birds may be lifeless in severe cases (Katty, 2013).

\section{Frostbite Treatment}

1. Move a frostbitten bird to a warmer location upon discovering of a severe case of exposure where tissue is black or large area of tissue are affected to stop any further cold injury from progressing.

2. Obtain veterinary care immediately if possible, for prescription medication for pain and inflammation. Metacam is commonly prescribed for this purpose. Alternately, 5 Asprin (5 grain each) dissolved in one gallon of water may be given for 1-3 days

I recommend vetericyn VF hydrogel spray 2-3 times per day until healed after cleaning or antibiotic ointment or aloe vera can be applied to the damage tissue.

3. Gradually warm affected area(s). Frostbitten feet should be immersed in lukewarm water between $100^{\circ} \mathrm{F}$ and $101^{\circ} \mathrm{F}$ for $20-25$ minutes to bring the tissue back up to temperature slowly. For combs and wattles, wash cloths soaked in lukewarm water can be held very gingering against them. Avoid rubbing or any friction that could cause additional damage to tissues.

Note: Do not begin the warming process until the birds is no longer exposed to the cold. Thawing and refreezing of the tissues will cause greater damage than a delayed response to the initial injury would. Do not use direct heat such as heat lamp to thaw the affected area.

4. Do not rub or massage the affected area. It can damage the tissues further.

5. Do not break any blisters. They are Nature's Band-Aids and help protect the underling tissues.

6. Do not remove any blackened/dead tissue as it is protecting healthy tissue underneath it (Katty, 2013).

\section{RESILIENCE OF POULTRY TO COLD STRESS.}

- $\quad$ Birds require extra energy to keep than warmed during cold weather. So extra heat increments is to be provided. Extra handful of corn can provide this energy to keep the birds warm. Oats, barley and other energy input can be provided under cold stress.

- The drinkers can be wrapped up in a layer of bubble, wrap to help prevent freezing and adding slightly warmer water in the morning help keep in unfrozen for longer time.

- Adding vitamins and electrolytes to the drinking water can help with the shock of the cold injury.

- Do monitor the bird's dietary intake-the pain caused by wattles touching feeders and drinkers may deter it from eating and drinking. Birds will appreciate a poultry nipple watering system over a traditional drinker 
because their injured wattles will not touch the nipple system. This also prevents birds from spilling their drinking water in the coop.

- Keep litter dry, fresh and clean water in the coop. the use of sand is highly recommended as litter inside the birds coop because it evaporates moisture more rapidly than other litter and stay drier as a result. Sand also retains warmth better than any other bedding and given its high thermal mass and it will keep coop's temperatures more stable than other litter choices such as wood shavings and straw.

- Select cold handy breeds with small combs and wattles in very cold climates if possible.

- Provide a heat source if necessary, but do not use a dangerous heat lamp instead use ales hazardous form of heat such as radiant heat.

- A well ventilated coop should be provided particularly the roost area.

- Apply any of the following: Vaseline/petroleum jelly/ coconut oil, to their combs and wattles prior to roosting each evening. (Tilly, 2013) (Katty, 2013).

\section{CONCLUSION}

Cold and heat stress are challenges to poultry farming during hot and cold climate, which could lead to reduced feed consumption, (poor feed intake and poor feed conversion) low productivity, decreased egg production, reduced egg shell quality and size, reduced hatchability rate and survivability decline. There is no single solution to hot and cold weather problems but following adaptive measures are necessary to minimize agribusiness losses due to cold and heat stress:

$>$ Installation of evaporative cooling system on poultry farms.

$>$ Withdrawal of feeding during hot part of day

$>$ Provision of fresh drinking water $\left(5^{\circ} \mathrm{C}\right)$ with vitamin $\mathrm{C}$, electrolytes and sodium bicarbonate in hot part of the day.

$>$ Use of summer feed formula.

$>$ Avoid overcrowding of birds during hot climate.

$>$ Birds should be handle as calmly and as gentle as possible to avoid additional stress.

Also we may not be able to avoid frostbite completely in the extensive system, but with a little forethought and some planning we can drastically reduce the number of losses and severity of frostbite when it does occur by preventing and treating frostbite using the tips in this write up. By understanding cold and heat stress and taking steps to prevent it, you will be keeping your birds comfortable and still be living the weather whether cold or hot.

\section{RECOMMENDATIONS}

1. Workshops and seminars should be organized for poultry attendants for capacity building and also in creating awareness on resilience of poultry production to climate change stress.

2. Poultry producers should ensure that all staffs are able to recognize the early signs of cold and heat stress and that the senior stockmen (managers) and other staffs (attendants) are familiar with the ventilation systems built into the poultry house.

3 Early warning plans should be made in advance to deal with hot and cold climate emergencies such as action to be taken and by whom both during normal operations and while other activities are carried out such as vaccination and restocking during climate change.

4. There is need for potential use of naked neck and frizzle strains of birds during hotter climate and cold handy breeds' with small combs and wattles in very cold climate.

\section{REFERENCES}

[1] Basillo V. De, Valerino M. , Yahav . S. and Picard . M (2001). Early Age Thermal Conditioning And A Dual Feeding Program For Male Broiler Challenged By Heat Stress. Poultry Science 80: 29-36.

[2] Charles D.R, (2002). Responses To The Thermal Environment. In Charles D.A and Walker A.W (eds). Poultry Environmental Problems. A guide to solutions. Nottingham University Press,

[3] Nottingham, UK. pp. 1-16.

[4] Czarick .M. and Lacy .M, (2000).Poultry Housing Tips. Importance of Air Movement Versus Birds Age. The Poultry Informed Professional, July.

[5] Defra, (2003) Heat stress in poultry-solving the problem.

hrrp://www.defra.gov.uk/animal/welfare/farmed/mestch $\mathrm{ks} / \mathrm{pb} 1315 / \mathrm{streetoc.htm}$.

[6] Elsevier, (1996). Inc. Volume 58 Issue 1-2, page 127147. Jordon, F.T.W (1990). Poultry Disease.

[7] Bailiere Tindall. $3^{\text {rd }}$ Edition London.

[8] Katty S.M, (2013). Frostbite in Backyard Chickens: causes, treatment and prevention.

[9] http://www.the-chicken-chick.com/2013/12/frostbite-inbackyard chicken.

[10] Kenneth E.A , (2007) Extension Poultry Specialist, Thomos A.C, Specialist in charge, poultry Science Extension.North Carolina State University. 
[11]Kutlu H. R. (2001) Effect of wet feeding and supplementation with ascorbic acid and on performance

[12] and carcass composition of broiler chicks exposed to a high temperature. Archiv fur Tienrernahrung 54: 127139.

[13] Lavergn, (2014).LSU AgCenter New Publication.

[14]Leeson .S, (2000).Broiler Feed Management During Heat Stress. Department of Animal and Poultry Science, Guelph. Ontario.

[15]Lin H, Jiao H.C, Buyse .J and Deuypere. E,(2006). Strategies For Preventing Heat Stress in Poultry.

[16] World Poultry science Journal 62:71-86.

[17] McMullin P, (2004).A Pocket Guide to Health and Disease. $\quad$ http://www.poultry.com/books/b34lapocket-giude- to-poultry-health-and-disease

[18] Narsapur V.S. (2012), Heat Stress and Associated Problems in Poultry.

[19] Poultryone, (2008). Ways to Avoid the Heat, Cooling Devices and Heat Stress Prevention Methods. http://www.poultry.com /articles/heat.html.

[20] Tadtiyanant C., Lyons J.J. and Vandepopuliere J.M. (1991). Influence of Wet and Dry feed on Laying Hens under Heat stress. Poultry Science 70: 44-52

[21] Teeter R.G, T.Belay, F.Deyhim, and Cason J.J, (2000). Heat Stress Steals Nutrient and Genetics

[22] Potential. Department of Animal Science, Stillwater, Oklahoma.

[23] Tilly'sNest, (2013). Frostbite in Backyard Chickens.

[24] http://www.tillysnest.com/2013/01/frostbite-andbackyard-chickens.html. (pp 174).

[25] Would Poultry, ( 2010).An Article Publication on Managing Heat Stress.

[26] WVA, (2005).Save Poultry Industry by Heat Stress Management. World Veterinary Association.

[27] http://www.worlvet.org/modules.ph 